\title{
Travel mode choice preferences of urban commuters in Kuching City, Malaysia based on stated preference data
}

\author{
Resdiansyah ${ }^{1, *}$ \\ ${ }^{1}$ Universitas Pembangunan Jaya, Department of Civil Engineering, Bintaro, Indonesia.
}

\begin{abstract}
One aspect of Kuching City that has not progressed in tandem with the rest of the city is the public transport system, which is relatively old and almost non-existent. Transport and City planners seem to be at their wit's end in coming up with satisfactory solutions to Kuching's public transportation woes. In current situation, many proposals, but none have proven workable. As a result, representative buses remain a rare sight on Kuching city's roads. To achieve a sustainable public transport industry, the old buses need to be regenerated and replaced with modern buses. The objectives of the intended study are to explore the consumer's travel behaviour by employing mode choice modelling. Consequently, a study was conducted in Kuching City Area by using stated preference technique, analysed and compiled by using SPSS.17 multiple linear regressions analysis. In this context, discrete choice analysis was used to examine the relationship between independent variables (travel time, waiting time, fares and comfort) and dependent variables (choice of respondent whether to consume old bus or choose new bus services). A total of 2000 respondents were interviewed. The findings showed that for the trips purpose, fares and comfortability were the primary factors that reflected the decision or behaviour of the respondents asked. It was discovered that there is a significant relationship between the choice of the respondents and comfortability. It also appeared that longer travel time did not affect for the traveler's choice at this stage. Hence, the study suggests that the local authority and the bus operators should establish a "quality partnership" and working together in order to come out with a much better and appropriate transport policy and schemes for the existing public transportation systems, especially bus services.
\end{abstract}

\section{Introduction}

In Kuching City and the suburban areas, buses are the primary mode of public transportation system available. Currently, bus services in Kuching City Area are relatively old and most of the buses are in state of dilapidation. One aspect of Kuching that has not progressed in tandem with the rest of the city is the public transport system, which is almost non-existent. Transport and City planners seem to be at their wit's end in coming up with

* Corresponding author: 
satisfactory solutions to Kuching's public transportation woes. In current situation, many proposals, but none have proven workable. As a result, representative buses remain a rare sight on Kuching city's roads. Ironically, statistics show that only one per cent of the people in Kuching City use buses to move around the city, 87 per cent drive to work and five per cent ride their motorcycles. This explains why traffic congestion in Kuching City is getting from bad to worse. On the other hand, the usage of the motor vehicles (especially cars) has become inevitable to the people of Kuching as the public bus transport system is too old, not frequent and timely and there are not many other public transport options available.

Thus, to achieve a sustainable public transportation industry, the old buses need to be regenerated and replaced with modern buses, so people will start thinking to shift to public transportation. This study is to explore the travel behavior by employing mode choice modelling. In this context, stated preference (SP) technique was used to evaluate the traveler's behavior. Also, the study provides a simple overview of the design and implementation of stated preference techniques to estimate the importance of the mode attributes. SP techniques are very popular since it was applied, developed and accepted for the purpose on transportation behavior study in the last three decades. In SP techniques, the study presented the methods of discrete choice analysis based on mathematical modelling to analyze the travel demand and traveler's behavior in order to come out with the best criteria for the implementation of new public transportation schemes.

\subsection{Background of Public Transportation in Study Area}

Briefly, public transportation in Kuching City area is only focusing on the buses, though there are other modes of public transportation such as taxis and vans. Taxis can be easily found outside the hotels or at the taxis stands. Fares are reasonable, but should always be agreed in advance. Vans can be found at the city center adjacent to the India Street area. The fares are much cheaper compared to taxis. Generally, the service is quite similar to the taxis because they are operated independently.

However, vans do not serve the consumers who wish to travel within the city area of which buses and taxis are still the best option for this particular purpose. Bus services are the best option due to cheaper fares offered. Fares depend on the travel distance. Majority of the buses are not air-conditioned. On the other hand, there is no centralized and modernly built bus interchange in Kuching city. Most of the local bus terminals are separately located within the center of the city area (adjacent to the waterfront, India Street and along the Gambier Street. Additionally, departure points also vary and depend on the destinations/zones served and individual bus operators. There are five major bus operators in Kuching which are namely Bau Transport, Biaramas Express Bus, City Public Link Transport, Petra Jaya Transport and Sarawak Transport Company.

\subsection{Problem Statement and Objective}

As a result of rapid changes and competitive in the modern industry, the companies survival in the public transport services is largely depends on their great extent of capability to increase the patronage and influence the motorist travelers to shift their modes of mobility from car to public transport system. Generally, the preliminary intention of this study is to provide answers to the following questions:

a) How mode choice is affected by?

i. The level of services for both modes,

ii.Travel time,

iii. Waiting time, and

iv.Fares (cost), 
b) What are the travelers' behavior characteristics that influence their decision making in selecting modes of transportation?

The main objective of this study is to determine and compare the travel behavior of the existing and future bus passengers, in order to enhance its competitiveness and quality of services in the future. Specifically, the objectives of this study are arrayed as the followings:

i. To describe the characteristics of the public transportation demand by developing a model using SP technique with respect to some various scenarios for both of the buses, hence evaluate it by using discrete choice analysis.

ii. To evaluate the potential of the future exclusive and modern buses to cope with the current demand of the existing bus services in Kuching City area, where the results analysis is based on the journey purposes.

iii. To identify the response of the bus passenger according to the level of services such as comfortability, waiting time, travel time and cost offered by the bus operators.

\section{Conceptual framework of study}

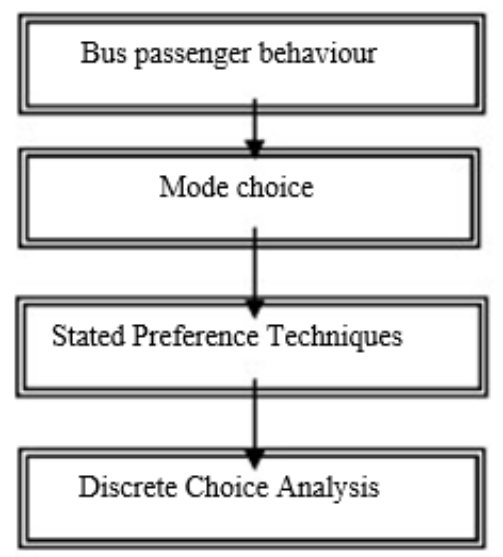

Fig 1. Conceptual Framework

The general steps of the study processes are summarised in Figure 1. The conceptual framework described here is mainly focused on the study of the bus user's behaviour. Eventually, the study will create a model, which will represent and determine the significance attributes of bus passenger behaviour that effect mode choice. A mode choice can be viewed as an outcome from the above sequential decision-making process. Thereafter, stated preference technique will be used to obtain the primary data from bus passenger. Finally, in order to describe the mode choice model, the researcher proposed to use a discrete choice analysis.

\subsection{Mode choice}

The choice of travel mode is probably the most important model in travel demand analysis. This is because the mode choice model is concerned with the trip-maker's behavior regarding the selection of travel mode. The reason underlying this choice varies between individuals, trip type, and the relative level of service and cost associated with the available models [1]. The objectives of mode choice models can be classified as: 


\subsection{Aggregate}

To estimate the number of proportion of trips from each zone to each zone by purpose that take any mode.

\subsection{Disaggregate}

To estimate the probability that a particular trips from each zone to each zone by a specific individual will take mode. But contemporary mode choice models are almost disaggregate model. So, in this study, mode choice models are basically disaggregate mode choice model. Disaggregate as used here means that models are intended to describe the mode choice made by individuals rather than by large groups or zonal [2]. It is interesting to see how far we can get by using a series of mathematical techniques. To summarize, there is a number of mathematical models are used to predict mode choice. These generally attempt to estimate the probability of a trip-maker's movement will use a particular mode. Several mode choice models forms are used. This includes binary logit model, multinomial logit model, hierarchical logit model, multinomial logit model, choice by elimination and satisfaction, utility and disutility function, probabilistic model and many other approaches. But, in this study the researcher will only focusing in binary logit model.

\subsection{Discrete choice analysis theory}

A discrete choice analysis based on random utility theory, has been the backbone of transport planning since the 1970s. It predicts a decision made by an individual (choice of mode, choice of route, etc.) as a function of any number of variables. The models are used when the consumption of one good rules out the consumption of another good, such as for example in travel mode choice situations [3]. As mention earlier, the models are a mathematical function, which predicts an individual's choice based on the utility or relative attractiveness of competing alternatives. The model generally includes characteristics of the individual and relative attributes of competing choices.

\subsection{Binary Logit Model}

Although there are a number of mathematical utility function in discrete choice models, but the most basic mathematical utility function for the models are as follows [4]:

$$
\begin{gathered}
U=U\left(q_{1}, q_{2}, q_{3}\right), \text { where, } \\
q_{1}= \begin{cases}1 & \text { If mode } 1 \text { is chosen, } \\
0 & \text { Otherwise; }\end{cases} \\
q_{2}= \begin{cases}1 & \text { If mode } 2 \text { is chosen, } \\
0 & \text { Otherwise; }\end{cases} \\
q_{3}= \begin{cases}1 & \text { If mode } 3 \text { is chosen, } \\
0 & \text { Otherwise; }\end{cases}
\end{gathered}
$$

and that only one alternative is chosen:

$$
q_{1} q_{2}=q_{1} q_{3}=q_{2} q_{3}=0 .
$$


For the purpose of this study, binary logit model was chosen since there were only two scenarios involved in the study. The derivation of any binary choice model is conceptually straight forward [4]. The utility function for binary logit models are as follows [4, 5, 6]:

$$
\begin{gathered}
P_{1}=\frac{e_{V_{1}}}{\overline{V_{1} V_{2}}} \\
(e+e)
\end{gathered}
$$

Where; $\mathrm{P} 1$ = Probability of the passenger to choose one of the scenarios, $\mathrm{e}=$ Exponential, $\mathrm{v}=$ Variable.

\subsection{Stated Preference Technique}

SP techniques can be described as a "family" of techniques, which individual respondent's statements about their preferences in a set of transports options to estimate utility functions $[7,8]$. It was designed to answer questions, which could not be answered with revealed preference (RP) techniques. This is due to the fact that it is often very difficult to undertake a "revealed preference" (RP) study and to derive meaningful results. Basically, RP techniques are based on the actual, observed behavior and applied in a real-world condition. While SP technique are based on hypothetical and stated behavior.

In spite of their known limitation and problems, SP based survey techniques have become an accepted part of the transport planning tool kit [7]. They also mention that SP techniques are implemented as stated-choice experiments, in which respondents are asked to choose between two or more alternatives described to them. The summarize of the main features of SP technique as follow [9, 10]:

i. It is based on the elicitation of respondent's statements of how they would respond to different hypothetical (travel) alternatives;

ii. Each option is represented as a 'package' of different attributes like travel time, price, headways, reliability and so on;

iii. The researcher constructs these hypothetical alternatives so that the individual effect of each attribute can be estimated; this is achieved using experimental design techniques that ensure the variations in the attributes in each package are statistically independent from one another;

iv. The researcher has to make sure that interviewees are given hypothetical alternatives they can understand, appear plausible and realistic, and relate to their current level of experience;

v. The respondent state their preferences towards each option by either ranking them in order of attractiveness, rating them on a scale indicating strength of preference or simply choosing the most preferred option from a pair or group of them;

vi. The responses given by individuals are analyzed to provide quantitative measures of the relative importance of each attribute.

\subsection{Identification of attributes}

In this study, attributes are generally defined as the variables, which describe and define the differences between the alternatives. The attributes may involve travel time, waiting time (frequency), cost (in terms of fares), comfortability, safety, reliability, interchange, headway and others. However, the design is simple, where there were only four attributes chosen which are the travel time, waiting time (frequency), cost (in terms of fares) and 
comfortability. Alternatives were the existing and future buses of which the respondents should make their option. And the levels are the values of the attributes, which are shown in Table 1.

\subsection{Experimental design}

At this stage, the researcher will design the way in which the options will be presented to the respondents and how they be allowed to express their preferences. The form of presentation of the alternatives will be easy to understand and within the context of the respondent's experience and constraints. For simplicity, the experimental design considered only four attributes:

i. travel time - varies (the three levels)

ii. waiting time (frequency) - varies (three levels)

iii. cost (in terms of fares) - varies (two levels)

iv. comfort -varies (two levels)

Thus, for a null factorial design, we need $22 \times 32=36$ option of combinations and these are described in appendix.

Table 1: Definition of levels for each attribute.

\begin{tabular}{cc}
\hline \multicolumn{2}{c}{ Attributes Levels } \\
\hline \\
Fast 20 \\
Travel time (min) Medium/ Original 25 \\
Slow 30 \\
Frequent 10 \\
Frequency (min) Medium/ Original 15 \\
Infrequent 20 \\
Fares (RM) \\
High 2.00 \\
Normal/ Original 1.60 \\
Comfort ability High Good \\
Low/ Original Poor \\
\end{tabular}

\subsection{Scenario design}

A certain number of scenarios has been defined and simulated as follows:

Table 2: Scenario Design

\begin{tabular}{ccccc}
\hline Scenario & $\begin{array}{c}\text { Travel Time } \\
(\mathbf{m i n})\end{array}$ & $\begin{array}{c}\text { Frequency } \\
(\mathbf{m i n})\end{array}$ & $\begin{array}{c}\text { Fares } \\
(\mathbf{R M})\end{array}$ & Comfort \\
\hline Current Situation & 25 & 15 & 1.60 & Poor \\
I & 25 & 15 & 2.00 & Good \\
II & 25 & 10 & 2.00 & Poor \\
III & 30 & 15 & 2.00 & Good \\
IV & 30 & 10 & 1.60 & Poor \\
V & 20 & 20 & 2.00 & Good \\
VI & 20 & 15 & 1.60 & Poor \\
\hline
\end{tabular}




\section{Modelling, results and discussions}

The model development in this study has covered dependent variable and independent variable. Dependent variable is the choices of the respondent whether to choose the new bus services or resume the current bus services. Independent variables were fares, travel time, frequency (waiting time) and comfortability. Additionally, the models developed in the study were also based on the different consumers' trip purposes. The model is given by:

where;

$$
U=a 1+a 2(T C-T N)+a 3(W C-W N)+a 4(F N)
$$

$$
\begin{aligned}
& \mathrm{U}=\text { Utility function } \\
& \text { a1 = constant (independent variable) } \\
& \text { a2 }=\text { constant for travel time (dependent variables) } \\
& \text { a3 = constant for frequency (dependent variables) } \\
& \text { a } 4=\text { constant for fares (dependent variables) } \\
& \mathrm{T}=\text { travel time } \\
& \mathrm{W}=\text { frequency (waiting time) } \\
& \mathrm{F}=\text { fares } \\
& \mathrm{C}=\text { current bus } \\
& \mathrm{N}=\text { new bus }
\end{aligned}
$$

SPSS 17.0 (multiple regression analysis method) was used to develop the models for different trips purposes, which are tabulated in table 3 below:

Table 3. Model development

\begin{tabular}{lc}
\hline \multicolumn{1}{c}{ Journey Purpose } & Model \\
\hline School & $U=-4.947+0.028\left(T_{C}-T_{N}\right)+0.020\left(W_{C}-W_{N}\right)+2.708\left(F_{N}\right)$ \\
Work & $U=-4.535+0.023\left(T_{C}-T_{N}\right)+0.024\left(W_{C}-W_{N}\right)+2.519\left(F_{N}\right)$ \\
Social/Recreation & $U=-4.842+0.026\left(T_{C}-T_{N}\right)+0.011\left(W_{C}-W_{N}\right)+2.763\left(F_{N}\right)$ \\
Shopping & $U=-5.002+0.033\left(T_{C}-T_{N}\right)+0.011\left(W_{C}-W_{N}\right)+2.790\left(F_{N}\right)$ \\
Other & $U=-6.066+0.029\left(T_{C}-T_{N}\right)+0.006\left(W_{C}-W_{N}\right)+3.450\left(F_{N}\right)$ \\
\hline
\end{tabular}

Figure 2 illustrates the summary of modelling results based on five different scenarios. For the trips purpose to school, recreation, shopping and others, most of the respondents preferred to opt for scenario 5 (travel time $20 \mathrm{~min}$, frequency $20 \mathrm{~min}$, fare RM 2.00, and the level of comfort is good with AC system) which gave the highest demand with the percentage of $75.4 \%, 55.1 \%, 70.3 \%$ and $69.1 \%$ respectively. On the other hand, scenario 3 (travel time $30 \mathrm{~min}$, frequency $15 \mathrm{~min}$, fare RM 2.00, and the level of comfort is good with $\mathrm{AC}$ system) was chosen for the purpose of working trips with the percentage of $50.5 \%$ respectively. The study revealed that most of the respondents preferred to choose scenario 5 except for working trips purposes where scenario 3 was chosen as the highest utility function. It also appeared that comfortability influences the behaviour of the respondents in making their decision of choosing the new bus system. For scenario 3 in particular, it is impossible for the bus operators to deliver new buses with equal price and at the same time provide a greater comfortability. Consequently, it can be concluded that scenario 5 is the most appropriate condition to be adopted and implemented by the bus operators in time to come, where the bus operators should provide a better bus services which are comfortable with a reasonable fare. It appeared that longer travel time did not affect the bus passenger choice for the current condition of bus services in Kuching city area. 


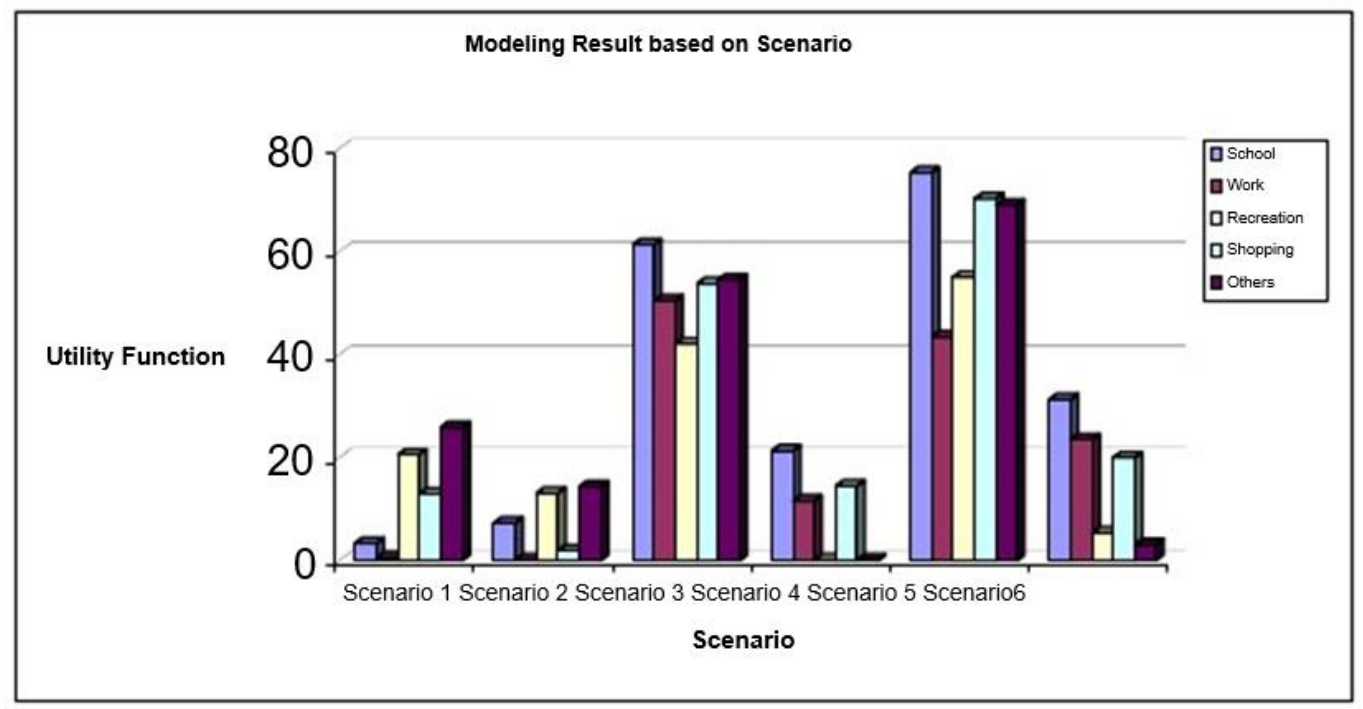

Fig. 2 Model Application Based on Scenario

\section{Conclusions and recommendation}

The study findings showed that for every trip purposes, fares and comfortability influence the decision making or behaviour for most of the bus consumers asked. The probability for the new bus services scheme to compete with the current bus is generally very moderate. This is due to the fact that majority of the respondents asked have chosen a good level of services especially comfortable with a reasonable price (fares). In line with the study, significant relationship between the choice of the respondents and comfortability has been discovered.

Considering wider implications of the present findings, it seems necessary to conduct a more thorough and comprehensive study regarding the travel behaviour of bus passengers, which also suggests that further studies should be conducted that involve all the public transportations users and the potential users (private car users). A bigger sample size would give further corroborative evidence about the behaviour of the public transportations users. Future researchers should consider conducting studies in other locations in order to compare the findings. Consequently, a clearer understanding regarding the public transportations users' behaviour could be achieved as a result. Importantly, the local authority and the bus operators should establish "quality partnership" and work together in order to successfully implement and achieve a better result for the public transports users which at the same time able to attract car commuters to change their mode of transportation to buses.

\section{Acknowledgements}

This research was partially funded by North Kuching City Council, East Malaysia and Universiti Malaysia Sarawak. 


\section{References}

1. Papacostas, C.S. Fundamentals of Transportation Engineering, New Jersey: Prentice Hill Englewood. (1987).

2. Wright, P.H., Ashford, N.J., Stammer, R.J. Transportation Engineering: Planning and Design, 4th Edition. New York: John Wiley and Sons, Inc. (1998).

3. Nerhagen, L. Mode Choice Behaviour, Travel Mode Choice Models and Value of Time Estimation - A Literature Review. Dalarna University, T\&S. (2000).

4. Ben-Akiva, M., Lerman, S.R. Discrete Choice Analysis. Massachusetts: MIT Press. (1993).

5. Nasrullah, N., Parung, H., Ali, N., Ramli, M.I. Study of behavior transition to user moda personal transport public transport on the way in the district Takalar. International Journal of Civil Engineering and Technology (2017).

6. Hakim, R., Ramli, M.I., Aly, S.H., Rahim, R. A choice model on trip mode chain for inter-islands commuters in North Molucca-Indonesia: A case study of the Ternate Island - Halmahera Island trip. International Journal of Civil Engineering and Technology (2017).

7. Danielis, R., Rotaris, L. Analysing Freight Transport Demand Using Stated Preference Data: A survey and a Research Project for the Friuli-Venezia Giulia Region. (2003).

8. Nur, N.K., Samang, L., Isran Ramli, M., Hamid, S. Study of modes transformation preferences of private transport based on travel characteristics and user behavior. International Journal of Applied Engineering Research (2016).

9. Axhausen., Koll., Stern, E., Salomon, I., Bovy, P.H.L. Travel Behaviour: Spatial Patterns, Congestion and Modelling. Cheltenham: Edward Elgar Publishing Limited. (2002).

10. Ortúzar, J.D., Willumsen, L.G. Modelling Transport. Chichester: John Wiley and Sons Limited. (2011). 